\title{
QUEEN'S
UNIVERSITY
BELFAST
}

\section{Suffering third-party intervention during fighting is associated with reduced mating success in the fallow deer}

Jennings, D. J., Boys, R. J., \& Gammell, M. P. (2018). Suffering third-party intervention during fighting is associated with reduced mating success in the fallow deer. Animal Behaviour, 139, 1-8.

https://doi.org/10.1016/j.anbehav.2018.02.016

Published in:

Animal Behaviour

Document Version:

Peer reviewed version

Queen's University Belfast - Research Portal:

Link to publication record in Queen's University Belfast Research Portal

Publisher rights

(C) 2018 The Association for the Study of Animal Behaviour. Published by Elsevier Ltd. All rights reserved.

This manuscript version is made available under the CC-BY-NC-ND 4.0 license http://creativecommons.org/licenses/by-nc-nd/4.0/,which permits distribution and reproduction for non-commercial purposes, provided the author and source are cited.

\section{General rights}

Copyright for the publications made accessible via the Queen's University Belfast Research Portal is retained by the author(s) and / or other copyright owners and it is a condition of accessing these publications that users recognise and abide by the legal requirements associated with these rights.

Take down policy

The Research Portal is Queen's institutional repository that provides access to Queen's research output. Every effort has been made to ensure that content in the Research Portal does not infringe any person's rights, or applicable UK laws. If you discover content in the Research Portal that you believe breaches copyright or violates any law, please contact openaccess@qub.ac.uk. 
Suffering intervention and mating success in fallow deer

1 Suffering third-party intervention during fighting is associated with reduced mating success in the 2 fallow deer

3

4

5

Dómhnall J. Jennings ${ }^{1}$, Richard J. Boys ${ }^{2}$ \& Martin P. Gammell ${ }^{3}$

6

$7 \quad{ }^{1}$ Institute of Neuroscience, Newcastle University, Newcastle upon Tyne, NE2 4HH, UK

$8 \quad{ }^{2}$ School of Mathematics \& Statistics, Newcastle University, Newcastle upon Tyne, NE1 7RU, UK

$9 \quad{ }^{3}$ Department of Natural Sciences, Galway-Mayo Institute of Technology, Galway, Ireland

10

11 Correspondence: domhnall.jennings@ncl.ac.uk 
Suffering intervention and mating success in fallow deer

12 Numerous studies have shown that dyadic fights are regularly disrupted by the intervention of thirdparty group members. Empirical and theoretical attention with respect to these interventions have focused predominantly on the fitness advantages that accrue to the intervening individual; conversely, little attention has been given to studying the fitness implications of suffering from thirdparty intervention behaviour. Therefore, we investigated this issue by examining the relationship between variation in individual mating success and suffering third-party interventions during a fallow deer (Dama dama) rut. Mating success was analysed using a 'hurdle' model against three explanatory variables: daily variation in suffering an intervention, dominance rank and fight rate. The lower, logistic level of the model, indicated a negative interaction between variation in suffering an intervention and fight rate in relation to whether a mating was achieved or not. Further investigation of this interaction showed that the proportion of matings achieved by males declined as interventions suffered increased regardless of whether males had a high (five or more fights per day) investment in fighting. There was no meaningful effect observed in the upper level of the model. We also investigated whether there was evidence for a temporal association between suffering interventions and mating success: two models investigated interventions suffered on a previous day and the cumulative sum of interventions suffered over two days in relation to mating success. Neither model showed a meaningful association at the lower or upper level indicating that the effects of intervention behaviour are temporally limited in this population. Our results underline the complex nature of the relationships at play during third-party interventions in relation to mating success. We suggest that there is a need for greater empirical investigation and wider theoretical scrutiny with respect to suffering intervention.

Key words:

Bayesian model, dominance, fallow deer, fighting rate, mating success, third-party intervention. 
Suffering intervention and mating success in fallow deer

The study of animal contest behaviour in relation to outcome and fight dynamics has tended to focus on the importance of resource value and fighting ability (resource holding potential, RHP: Parker, 1974). Such considerations have led to the development of a number of influential models that focus on the decision processes used by combatants during fights (e.g. Payne, 1998; Taylor \& Elwood, 2003). A key aspect of these models is that they specifically address aggression at the dyadic level. However, there is accumulating evidence that contest behaviour can involve more complex forms of aggressive interaction. Specifically, a number of studies conducted on (semi-) captive (e.g. African wild dog, Lycaon pictus: de Villiers, 2003; raven, Corvus corax: Fraser \& Bugnyar, 2012; gelada, Theropithecus gelada: Pallante, Stanyon \& Palagi, 2016; Grant and Chapman zebra, Equus individuals frequently intervene and disrupt ongoing contests. Theoretical explanations underpinning the study of intervention behaviour have been largely driven by the extensive body of work conducted on primate species (Bissonnette et al., 2015; Smith et al., 2010). Such accounts typically emphasise that intervention behaviour serves to underpin the formation of coalitions; thus, individuals are expected to be able to track shifting dominance relationships (e.g. Chapais, 1995) or to remember past relationships (i.e. who helped who previously, e.g. Gavrilets, Duenez-Guzman \& Vose, 2008). Alternative accounts hold that individuals might simply disrupt dyadic fights in order to prevent successful rivals from advancing in the hierarchy via a winner effect (Dugatkin, 1998). Therefore, rather than coalition formation, intervention acts to maintain the social status quo by insulating high-ranking individuals from challenges by lower ranking adversaries (Jennings et al., 2009). Nevertheless, regardless of whether one appeals to a coalitionary or noncoalitionary account of third-party behaviour, the majority of 
Suffering intervention and mating success in fallow deer

these theories tend to argue that interventions serve to improve fitness by helping the intervener secure access to valuable resources.

Nonetheless, determining whether intervention confers fitness benefits has proven to be difficult. For example, benefits might accrue directly (e.g. an increase in rank: Jennings, Carlin, Hayden \& Gammell, 2011), or indirectly (e.g. kin support: Engh, Siebert, Greenberg \& Holekamp, 2005). However, despite numerous studies the relationship between reproductive opportunities and triadic behaviour is not clear-cut. Consequently, few studies have shown that third-party intervention behaviour benefits individuals with respect to mating success (but see Jennings et al., 2011; Gilby et al., 2013). One possibility is that the lack of evidence supporting such a relationship might be due to the temporal relationship between intervention behaviour and the fitness outcome (Harcourt \& de Waal, 1992). From a coalitionary perspective for example, it is possible that the degree of (in)stability in the nascent relationship between individuals introduces a temporal lag between intervention acts, and the accrual of any actual benefits. Although we are not aware of any studies that focus specifically on the temporal relationships between intervention behaviour and mating success, coalitionary behaviour (which includes third-party behaviour) tends to peak just prior to the most likely day of conception in the baboon (Bercovitch, 1988). In terms of improvement in rank the evidence is somewhat mixed; for example, temporal lag appeared to be minimal with respect to male rank advancement in chimpanzees (e.g. de Waal, 1982; 1984), whereas in macaques there was little evidence that intervention was associated with an increase in rank over time (e.g. Silk, 1993). Given that there has been relatively little investigation of this question, one objective of this study is to gain a more comprehensive understanding of the temporal association between intervention behaviour and mating success.

While a general finding shows that dominance rank is positively associated with mating success in many species (Dewsbury, 1982; Ellis, 1995), the evidence that the relationship between third-party behaviour and fitness is influenced by dominance rank is more limited (e.g. de Waal 1984), albeit theoretically expected (e.g. Chapais, 1995; Dugatkin, 1998; van Schaik, Pandit, \& Vogel, 
Suffering intervention and mating success in fallow deer

2006). Whether the same relationships hold for recipients of third-party intervention behaviour has received little attention. While it has been reported that the costs to individuals of suffering an intervention can be severe in terms of consortship with females (e.g. Noë, 1992), we are unaware of any detailed studies that have investigated the relationship between suffering third-party intervention, dominance and fitness. We might speculate that depending on the way in which dominance interacts with intervention behaviour, a negative (lower ranks depose higher ranks revolutionary) or positive (higher ranks defeat lower ranks - conservative) interaction between suffering an intervention and dominance should hold in relation to fitness. Nonetheless, theory is generally silent on the matter; therefore, one possibility investigated here is whether suffering intervention is associated with fitness via an interaction with dominance rank.

However, if we ignore the bulk of theoretical and empirical work on third-party behaviour, perhaps the most parsimonious explanation is that irrespective of rank, a direct negative impact of suffering intervention on mating success is expected. Specifically, the intervener behaves opportunistically in disrupting ongoing fights (Jennings et al., 2009, 2011); therefore, rather than interacting with dominance, suffering an intervention should be directly associated with reduced mating success. An alternative possibility is that intervention behaviour forms part of the general aggressive repertoire of males as they compete for mating opportunities (Jennings, Boys, \& Gammell, 2017). Therefore, suffering from intervention might well interact with other aspects of competitive behaviour such as fighting (see de Waal \& Harcourt, 1992 for a discussion of facial and vocal signals aligned with triadic behaviour); therefore, in relation to fitness, an interaction between fighting and suffering from intervention might be expected.

Male fallow deer display a heightened tendency to fight with conspecifics during the annual rutting season (e.g. Apollonio, Festa-Bianchet, Mari, Mattioli \& Sarno, 1992; Clutton-Brock, Green, Hiraiwa-Hasegawa \& Albon, 1988; Moore, Kelly, Cahill \& Hayden, 1995), and approximately ten percent of fights are disrupted by the intervention of third-party males (Jennings et al., 2009). To date, studies have focussed almost exclusively on intervention behaviour in relation to the 
Suffering intervention and mating success in fallow deer

intervener rather than the recipient of the intervention; these have shown that intervention is associated with increased mating success (Jennings et al., 2011), and is most likely to be committed by high-ranking males (Jennings et al., 2009). Furthermore, the tendency for individuals to engage in interventions varies based on aggression experienced, rather than resource access. Therefore, the number of different opponents fought, and whether the individual itself suffered from fight interventions on a given day, rather than the number of mating opportunities available are important correlates of intervention behaviour (Jennings et al., 2017). Taken together, these findings indicate that it is males at the upper end of the hierarchy (Jennings, Gammell, Carlin, \& Hayden, 2006), i.e. those most likely to mate, that are most likely to disrupt each other's fights. The question we ask here is why, and to what end? Given the lack of empirical studies on this question, and in the absence of theoretical direction, we sought to investigate a number of possibilities in relation to the impact of suffering third-party behaviour on fitness.

We sought to determine whether there was evidence for any detrimental effect of suffering an intervention on mating success by examining whether any association between suffering intervention and mating success was direct or via an interaction with dominance and fighting - two variables that correlate with mating success (Clutton-Brock, Albon, Gibson \& Guinness, 1979; Moore et al., 1995). Given that numbers of oestrus females represent a variable resource over the course of the rut, we also investigated the temporal relationship between variation in suffering from intervention and any potential fitness gain (e.g. Bercovitch, 1988; de Waal, 1984; Silk, 1993). Therefore, we investigated whether any association between suffering an intervention and mating success was temporally proximate (evident on the same day) or delayed (evident on the following day). 
Suffering intervention and mating success in fallow deer

\section{Methods}

137

Study population: Aggressive behaviour in a herd of free-ranging fallow deer resident in Phoenix

Park, Ireland $\left(53^{\circ} 22^{\prime} \mathrm{N}, 6^{0} 21^{\prime} \mathrm{W}\right)$ was recorded from late August/early September and throughout the annual rut in the latter half of October during two successive years (1996/1997). The park encloses 709 hectares; the majority of the area of the park ( $80 \%$ approximately) is open grassland with the remaining area consisting of mixed woodland. The management plan for the deer involves tagging fawns shortly after birth (annually between June and July) with a uniquely coloured and numbered ear tags. Approximately $95 \%$ of mature males (4 years or above) retained possession of their ear tags, and we used these in combination with coat colour and differences in antler shape and size to identify individuals. There were 79 individually identifiable males included in this study: 65 males in 1996 and 62 males in 1997, with 48 males present in both years, and 31 present in only one year of the study. We excluded males from the analysis because they joined the rut late, thus, had no ranking for some days, or they died prior to or during the rut.

Observation protocols: The deer in this population form sexually segregated herds occupying distinct home ranges for much of the year (Moore et al., 1995). Between August and September, whilst males still resided in a cohesive single-sex group (bachelor herd), they were monitored daily (between 9am-5pm) Monday to Friday by two to three observers. During late September, the bachelor herd gradually disperses to the female range and males increasingly exhibit typical rutting behaviour (e.g. fighting, vocalising, scent marking), and show a heightened interest in females (e.g. herding, sniffing, Chapman \& Chapman, 1975). At the beginning of October, the number of observers and the observation schedule increased such that approximately 10 observers were in the field between dawn and dusk seven days per week. 
Suffering intervention and mating success in fallow deer

161

162

163

164

165

166

167

168

169

170

171

172

173

174

175

176

177

178

181

182

Data Analysis. Daily variation in mating success was investigated in relation to three different regressors (see below for details) between the $14^{\text {th }}-31^{\text {st }}$ of October when the majority of matings occur (Moore et al., 1995). We recorded the outcomes of aggressive interactions and the identities of the protagonists using all-event sampling (Altmann, 1974). Dyadic aggression was divided into two categories: (i) non-contact interactions where one male approached and displaced his opponent without making physical contact and (ii) fights.

The first regressor, the number of interventions suffered per day, represented the variable of interest in the present study ( $N=600$, Mean $=0.26, S D=0.6$ per male/day, Jennings et al., 2017). The second regressor was the number of dyadic fights each mature male engaged in that ended without suffering an intervention ( $N=3548$, Mean $=1.55, \mathrm{SD}=2.3$ per male/day). The third regressor used the Elo-rating method $(E l o, 1978)$ to investigate daily variation in dominance rank (see supplementary file for raw data). The Elo-rating method was selected as it differs from other methods because it does not calculate the hierarchy based on a summary matrix at the end of a defined period of time (Briffa et al. 2013). Rather it updates the dominance rank of individual males based on contests as they occur meaning that the order in which contests occur may influence the rating each individual is awarded. We calculated an initial Elo-rating for each male based on the outcome of all decisively resolved non-contact interactions recorded from late August/early September to October $14^{\text {th }}$. Thereafter, we recalculated the Elo-rating using only non-contact interactions each day until October $31^{\text {st }}$ in order to estimate how dominance rank varied for each individual (see Figure 1).

\section{Insert figure 1 about here}


Suffering intervention and mating success in fallow deer

The present study analysed data using information on a day-by-day basis during the rut permitting us to account for the effects of day and year as categorical variables in the models. In addition, three random effects were included: individual identity of the males, and two interaction terms: (i) identity * day and (ii) identity * year (Jennings et al., 2017), because individual males can differ in both their willingness to engage in fighting and competitive ability over the course of the rut (e.g. refer to Figure 1 to see variability in dominance).

Three models are presented here: the first examined the association between variation in suffering an intervention and mating success on that day (a proximate model), and the second on the delayed association between suffering an intervention and mating success the following day (a delayed model). In the case of the delayed model, the outcome variable (mating success), and the two other regressors (dominance rank and number of fights) were offset by one day relative to the regressor for suffering an intervention; thus, interventions suffered on the $14^{\text {th }}$ were regressed against mating success on the $15^{\text {th }}$. Dominance rank and number of fights on the $15^{\text {th }}$ were regressed against mating success on the $15^{\text {th }}$ and so on. We included a third model to investigate if there was any cumulative effect of suffering an intervention: in this model the summed number of interventions suffered every two days was regressed against daily mating success. Thus, interventions suffered on the $14^{\text {th }} / 15^{\text {th }}$ of October were summed and regressed against mating success on the $15^{\text {th }}$ and so on. The other two regressors were held constant as in the proximate and delayed models; therefore, dominance rank and number of fights recorded on the $15^{\text {th }}$ were regressed against mating success on the $15^{\text {th }}$.

The statistical model: We used Bayesian methods to evaluate our data as it provides a more straightforward approach to analysing complex (e.g. hierarchical) models with latent structures (Kruschke 2015). The posterior distribution generated by MCMC was sampled using the freely available JAGS software package (4.2, Plummer, 2003) controlled within the RunJags package (2.0.4- 
Suffering intervention and mating success in fallow deer

2, Denwood, 2015) in R (3.3.3). Following the analytic approach in Jennings et al. (2017), we investigated the association between suffering third-party intervention and variation in mating success using a hierarchical 'hurdle' model. The model consisted of two levels: the lower level (the hurdle) used a logistic regression to investigate the effects of each regressor based on whether a male achieved a mating or not. The upper level was a truncated Poisson regression (because inclusion at this level was conditional on a mating being achieved), that addressed the effects of the regressors with respect to the number of mating achieved (see supplementary files for model code).

The model was run over three parallel chains that employed dispersed initial values. We employed an adaptive phase of 11,000 iterations (including burnin), following which a posterior phase of 0.5 million iterations was sampled. The posterior was thinned by taking every $1000^{\text {th }}$ iterate to reduce autocorrelation, and convergence was assessed using the Gelman-Rubin statistic (Gelman \& Rubin, 1992) - a convergence level of $<1.1$ for each model parameter indicated that the adaptive phase of the model was sufficient (Kruschke 2015). We used independent weakly informative normal priors for the regression coefficients, and a half-t prior for the random effect variances to reduce the influence on the posterior distribution (Gelman, Jakulin, Grazia-Pittau \& Su, 2008). Inferences concerning each model regressor were made based on the posterior mean and $95 \%$ credible confidence intervals. For the purpose of interpreting whether a regressor was meaningful, we inspected the central $95 \%$ posterior confidence intervals of each regressor and we considered there to be a meaningful effect of a regressor if less than $5 \%$ of the posterior distribution of the coefficients crossed zero (Allen, Street \& Capellini, 2017; Capellini, Baker, Allen, Street \& Venditti, 2015) . Where the posterior mean of the regressor coefficient was low (i.e. less than 0.02), we considered there to be no meaningful biological effect (Bridger, Bonner \& Briffa 2015). 
Suffering intervention and mating success in fallow deer

Inspection of the mean number of interventions suffered by individual males indicated that there interventions suffered, with a range of between zero and six interventions recorded per male per day.

Insert figures $\mathbf{2}$ and $\mathbf{3}$ about here

\section{The logistic model}

We examined the correlations in the posterior distributions of the three regressor coefficients in the models. In general, these were weakly correlated with the strongest positive correlation between the coefficients of daily variation in dominance and number of fights in the three models: the proximate model $(r=0.58)$, the delayed model $(r=0.35)$ and the cumulative model $(r=0.52)$. variation in dominance and number of fights were both positively associated with whether or not a male would achieve a mating (see Figure 4, the intercepts were excluded from the figure because the credible intervals were very wide: Proximate model: mean $-35.78 \% \mathrm{Cl}=-45.6,-26.2$; Delayed model: mean $=-36.1,95 \% \mathrm{Cl}=-46.2,-26.8$; Cumulative model: mean $=-37.4,95 \% \mathrm{Cl}=-48,-28.1$ ). However, since these models regressed essentially the same rank and daily fight rate data onto daily mating success this result is unsurprising. The association of interest here is the fate of the regressor relating to the number of interventions suffered: in all three models, there was no evidence of a direct association with variation in mating success. An examination of the percentage of the 
Suffering intervention and mating success in fallow deer

257

258

259

260

261

262

263

264

265

266

267

268

269

270

271

272

273

274

275

276

277

279

280

posterior chains indicated that $23 \%, 80 \%$ and $73 \%$ of the proximate, delayed and cumulative models were negative. Reference to the interaction terms indicated that there was a negative interaction between variation in interventions suffered and daily fight rate in the proximate model $(99 \%$ of the thinned posterior was negative) but no meaningful association in the delayed or cumulative models ( $45 \%$ and $93 \%$ of the thinned posterior chains were negative). No other meaningful interactions were observed. As expected in a population with a high skew in reproductive success the random effects component of the model showed a meaningful effect of individual and meaningful interactions between individual and year/day.

\section{Insert figure 4 about here}

In order to investigate the interaction between fighting and suffering an intervention in the proximate model we estimated, from the raw data, the proportion of matings achieved in relation to these two variables. We grouped the number of fights into three categories: no fights that day, 1-4 fights as this encompassed the average daily fight rate of males (2.3 fights per male per day), and five or more fights per day. As might be expected, the proportion of matings increased as males increased the number of fights per day they engaged in (Figure 5). Our data show that the proportion of matings was highest (47\%) when males engaged in five or more fights per day, and no interventions were suffered. Where a single intervention was suffered and males engaged in five or more fights, the proportion of matings decreased to $40 \%$. This decrease in mating success was more pronounced if two or more interventions were suffered; the proportion of matings was some $31 \%$ lower $(0.16$, Figure 5$)$ relative to when no intervention was suffered.

\section{Insert figure 5 about here}


Suffering intervention and mating success in fallow deer

282

283

284

285

286

287

288

289

290

291

292

293

294

295

296

\section{The Poisson model}

Inspection of the correlations of the posterior distributions of the three coefficients indicated weak or negative relationships. For the proximate model the correlation between interventions suffered and dominance was weak $(r=0.23)$; for the delayed model and cumulative models, the relationship between dominance rank and fighting was weak $(r=-0.31$ and -0.21 respectively). The upper level of the model showed that dominance rank was meaningfully associated with daily variation in mating success (see Figure 6, the intercepts were excluded from the figure because the credible intervals were very wide: Proximate model: mean $-0.2,95 \% \mathrm{Cl}=-4.5,4.8$; Delayed model: mean $=-0.2,95 \% \mathrm{Cl}$ $=-5.8,4.6$; Cumulative model: mean $=-0.4,95 \% \mathrm{Cl}=-5.3,4.8)$. With respect to the objectives of this study, however, the coefficient for variation in interventions suffered showed no meaningful main or interaction effects. The effect of individual identity and the interaction between identity and year/day was limited due to the low mating success of many individual males achieved during the rut.

Insert figure 6 about here 
Suffering intervention and mating success in fallow deer

\section{Discussion}

The present study investigates a variation on a question posed by Bissonnette et al. (2015): what are the potential fitness consequences of not participating (in coalitions)? Although fallow deer do not form coalitions, we note that coalitionary models are often underpinned by data derived from thirdparty behaviour. Therefore, we examined the fitness consequences of suffering from third party interventions. Thus, for the first time as far as we are aware, this study addresses the consequences of being an unwilling (or unwitting) recipient of a third-party interaction. The lower logistic level of our model showed that both dominance rank and fight rate were positively associated with whether or not a male would achieve a mating on any given day. At the upper level of the model, only variation in dominance rank was positively associated with mating success over the three statistical models. We chose dominance rank and fight rate because their relationship with mating success has been established in this population (e.g. Jennings et al., 2006; Moore et al., 1995), other ungulate populations (e.g. Clutton-Brock et al., 1979; Hogg \& Forbes, 1997; Wolf, 1998), and other species (e.g. Dewsbury, 1982; Ellis 1995; Colishaw \& Dunbar, 1991). Nevertheless, although they are not in themselves of concern here, they are theoretically relevant to the hypotheses examined. We wished to know whether the effects of suffering from interventions interacted with dominance rank or fighting, and whether any effects of suffering an intervention were immediate or delayed. examined time-periods ranging between months and years (e.g. de Waal, 1984; Silk, 1993); however, these long time-periods are less appropriate for this system. Intervention behaviour in this population occurs mainly during the relatively short duration of the annual rut where the oestrus female acts as a highly contestable resource that varies in abundance over days. Moreover, it is during this restricted time-period that the vast majority of fighting occurs (Jennings et al., 2009; Moore et al., 1995). Therefore, we concentrated our investigation to a more temporally proximate scale (i.e. variation on a day-by-day basis, Jennings et al., 2017). The analytic approach adopted here 
Suffering intervention and mating success in fallow deer

permitted us to investigate the relationship between suffering from intervention and mating success on two levels: a logistic model addressed whether individuals achieved a mating or not while the Poisson model addressed whether suffering intervention was associated with how many matings a male achieved.

From an inspection of the lower level of the model, it is evident that the effect of suffering an intervention differ between the three models as a function of the temporal relationship with mating success. There are immediate consequences at the lower level of the model for mating success as represented by the negative interaction between suffering an intervention and fight rate. Both the delayed and cumulative models showed no meaningful association, as either a main effect or interaction, indicating that the effects of suffering an intervention are temporally limited. It has been shown that estimates of the probability of mating are associated with age, dominance rank, fight rate, time of arrival at mating sites, ability to hold and defend a territory, body and antler size (e.g. Ciuti \& Apollonio 2016; Ciuti, de Cena, Bongi \& Apollonio, 2011; Jennings et al., 2006, 2011;Moore et al., 1995). The present study adds to this body of work. However, although we show that suffering from intervention behaviour affects the likelihood of mating, in common with many studies, our analytic approach failed to shed any light on the number of matings achieved by individual males. It may be that focussing solely on components of male aggression is too limited an approach and that further investigation of this issue may benefit by the inclusion of factors relating to female choice (e.g. Bro-Jørgensen, 2002).

Third-party behaviour can involve subordinate individuals acting as interveners, although the most commonly observed form of intervention tends to involve high-ranking individuals acting against subordinates (Bissonnette et al., 2015; Smith et al., 2010). Correspondingly, in the fallow deer it is high-ranking males that engage in third-party intervention behaviour against lower ranked individuals (Jennings et al., 2009), and experience a limited increase in dominance rank (Jennings et al., 2011). Critically, we failed to show the anticipated interaction between suffering from intervention behaviour and dominance. We note that in the particular case of rank changing 
Suffering intervention and mating success in fallow deer

coalitions, numerous interactions are required before a rank change may occur (van Schaik et al. 2006). Moreover, although individuals that engage in interventions in this population show increase in rank, there is little evidence that interveners are targeting specific individuals (Jennings et al., $2009,2011)$. Therefore, it is possible that suffering from interventions do not occur at a sufficiently high level to interact with rank in this population.

$$
\text { As noted above, the proximate model showed an interaction between suffering an }
$$

intervention and fight rate at the lower level of the model. Previously we have shown that there are small margins associated with both a winner effect, and increased mating success in relation to intervention behaviour (Jennings et al., 2009). The effects of disruption of an ongoing fight on the combatants are unknown in terms of a loser effect (Hsu \& Wolf, 1999); however, the interaction we observed might be explicable by appealing to the effects of previous experience. For example, the effect of prior experience on contest behaviour determines whether the individual will subsequently initiate a contest (e.g. Franck \& Ribowski, 1987; Schuett 1997, Hsu \& Wolf, 2001; McDonald, Heimstra \& Damkot, 1968). Although these studies relate to the effects of losing a contest, they are relevant in a general sense because suffering an intervention prevents an individual from winning as discussed by Dugatkin (1998), whilst incurring at least some of the costs associated with fighting (Briffa \& Sneddon, 2007). In line with such thinking, we have shown elsewhere that there is an increased probability of subsequent fights ending without victory, if the preceding fight is drawn (Jennings, Gammell, Carlin \& Hayden, 2004). Given that access to resources is often determined by the ability to successfully compete for that resource (Arnott \& Elwood, 2009; Parker, 1974), suffering an intervention may have a loser-like effect on the competitive ability of the recipient. It would be of theoretical and empirical interest to investigate this question in more detail.

The question as to whether third-party behaviour impacts on subsequent fitness has rarely been addressed (but see Gilby et al. 2013 for an investigation over seasons). As noted above, we have shown that suffering an intervention (as an interaction with fighting) is negatively associated with mating success. A central aspect of our findings is that this relationship is temporally 
Suffering intervention and mating success in fallow deer

short-lived. Given the unpredictable distribution in the number of oestrus females per day over the course of the rut (e.g. Apollonio et al. 1992), our results emphasise the complex interplay between different forms of competition and fitness over time. Whereas, previous studies have highlighted this complexity (e.g. Gilby et al., 2013), the present study underlines how short-term variation in competitive dynamics interact to affect fitness.

In conclusion, the present study represents an attempt to understand a neglected aspect of intervention behaviour: how does suffering from interventions affect fitness? We anticipated that suffering from third-party interventions might interact with dominance rank to reduce the probability of achieving a mating; however, this was not the case. Rather, this study presents two key findings: (i) that suffering third-party intervention interacts with fighting to reduce the probability of mating, and (ii) that this effect is temporally limited to the day on which the intervention(s) occur. We suggest that there is a compelling need for further study into the effects of suffering an intervention, and that studies of this type will provide a more complete understanding of the evolution of third-party intervention behaviour.

Acknowledgements: I would like to extend thanks to my colleagues at the Mammal Research Group at University College Dublin for their help in the field. I would also like to thank the editor, Dr Rose Thorogood, Dr Simone Ciuti and an anonymous referee for their helpful comments on an earlier draft of this paper. 
Suffering intervention and mating success in fallow deer

\section{References}

Allen, W., Street, S.E. \& Capellini, I. (2017). Fast life history traits promote invasion success in amphibians and reptiles. Ecology Letters, 20, 222-230.

Altmann, J. (1974). Observational study of behavior: sampling methods. Behavior, 49, 227-267.

Apollonio, M., Festa-Bianchet, M., Mari, F., Mattioli, S. \& Sarno, B. (1992). To lek or not to lek: mating strategies of male fallow deer. Behavioral Ecology, 3, 25-31.

Arnott, G. \& Elwood, R.W. (2009). Assessment of fighting ability in animal contests. Animal Behaviour, 77, 991-1004.

Bercovitch, F.B. (1988). Coalitions, cooperation and reproductive tactics among adult male baboons. Animal Behaviour, 36, 1198-1209.

Bissonnette, A., Perry, S., Barrett, L., Mitani, J.C., Flinn, M., Gavrilets, S. \& de Waal, F.B.M. (2015). Coalitions in theory and reality: a review of pertinent variables and processes. Behaviour, $152,1-56$.

Bridger, D., Bonner, S.J. \& Briffa, M. (2015). Individual quality and personality: bolder males are less fecund in the hermit crab Pagurus bernhardus. Proceedings of the Royal Society, B, 282, 20142492.

Briffa, M. \& Sneddon, L.U. (2007). Physiological constraints on contest behaviour. Functional Ecology, 21, 627-637.

Briffa, M., Hardy, I.C.W., Gammell, M.P., Jennings, D.J., Clarke, D.D. \& Goubault, M. (2013). Analysis of animal contest data. In, Animal Contests (I.C.W. Hardy \& M. Brifffa, eds), pp. 47-85. Cambridge University Press: Cambridge.

Bro-Jørgensen, J. (2002). Overt female mate competition and preference for central males in a lekking antelope. Proceedings of the National Academy of Sciences, 99, 9290-9293. Capellini, I., Baker, J., Allen, W.L., Street, S.E. \& Venditti, C. (2015). The role of life history traits in mammalian invasion success. Ecology Letters, 18, 1099-1107. 
Suffering intervention and mating success in fallow deer

Chapais, B. (1995). Alliances as a means of competition in primates: evolutionary, developmental, and cognitive aspects. Yearbook of Physical Anthropology, 38, 115-136.

Chapman, D., \& Chapman, N. (1975). Fallow Deer: Their Ecology, Distribution and Biology. Terence Dalton: Suffolk.

Clutton-Brock, T.H., Albon, S.D., Gibson, R.M., \& Guinness, F.E. (1979). The logical stag: adaptive aspects of fighting in red deer (Cervus elaphus L.). Animal Behaviour, 27, 211-225.

Clutton-Brock, T.H., Green, D., Hiraiwa-Hasegawa, M. \& Albon (1988). Passing the buck: resource defence, lek breeding and mate choice in fallow deer. Behavioral Ecology and Sociobiology, 23, 281-296.

Ciuti, S. \& Apollonio, M. (2016). Reproductive timing in a lekking mammal: male fallow deer getting ready for female estrus. Behavioral Ecology, 27, 1522-15320.

Ciuti, S., de Cena, F., Bongi, P. \& Apollonio, M. (2011). Benefits of a risky life for fallow deer bucks (Dama dama) aspiring to patrol a lek territory. Behaviour, 148, 435-460.

Colishaw, G. \& Dunbar, R.I.M. (1991). Dominance rank and mating success in male primates. Animal Behaviour, 41, 1045-1056.

De Villiers, M.S., Richardson, P.R.K. \& van Jaarsveld, A.S. (2003). Patterns of coalition formation and spatial association in a social carnivore, the African wild dog (Lycaon pictus). Journal of Zoology, London, 260, 377-389.

de Waal, F.B.M. \& Harcourt, A.H. (1992). Coalitions and alliances: a history of ethological research. In, Coalitions and Alliances (A.H. Harcourt, \& F.B.M. de Waal eds), pp. 1-19. Oxford University Press: Oxford.

de Waal, F.B.M. (1982). Chimpanzee Politics: Power and Sex among Apes. Jonathan Cape: London. de Waal, F.B.M. (1984). Sex-differences in the formation of coalitions among chimpanzees. Ethology and Sociobiology, 5, 237-251. 
Suffering intervention and mating success in fallow deer

Denwood, M. (2015). RunJags: Interface Utilities, Model Templates, Parallel Computing Methods and Additional Distributions for MCMC Models in JAGS. http://cran.rproject.org/web/packages/runjags/index.html

Dewsbury, D.A. (1982). Dominance rank, copulatory behavior, and differential reproduction. Quarterly Review of Biology, 57, 135-159.

Dugatkin, L.A. (1998). Breaking up fights between others: a model of intervention behaviour. Proceedings of the Royal Society, B, 265, 433-437.

Dugatkin, L.A. \& Earley, R.L. (2003). Group fusion: the impact of winner, loser and bystander effects on hierarchy formation in large groups. Behavioral Ecology, 14, 367-373.

Ellis, L. (1995). Dominance and reproductive success among nonhuman animals: a cross-species comparison. Ethology and Sociobiology, 16, 257-333.

Elo, A.E. (1978). The Rating of Chess Players, Past and Present. Arco Publishing: New York.

Engh, A.L., Siebert, E.R., Greenberg, D.A. \& Holekamp, K.E. (2005). Patterns of alliance formation and postconflict aggression indicate spotted hyaenas recognize third-party relationships. Animal Behavior, 69, 209-217.

Feh, C. (1999). Alliances and reproductive success in Camargue stallions. Animal Behaviour, 57, 705713.

Franck, D. \& Ribowski, A. (1987). Influences of prior agonistic experiences on aggression measures in the male swordtail (Xiphophorus helleri). Behaviour, 103, 217-240.

Fraser, O.N. \& Bugnyar, T. (2012). Reciprocity and agonistic support in ravens. Animal Behaviour, 83, 171-177.

Gavrilets, S., Duenez-Guzman, E.A. \& Vose, M.D. (2008). Dynamics of coalition formation and the egalitarian revolution. PLoS One 3: e3293. 
Suffering intervention and mating success in fallow deer

Gelman, A. \& Rubin, D.B. (1992). Inference from iterative simulation using multiple sequences. Statistical Science, 7, 457-511.

Gelman, A., Jakulin, A., Grazia Pittau, M. 7 Su, Y-S. (2008). A weakly informative default prior distribution for logistic and other regression models. Annals of Applied Statistic, 2, 13601383.

Gilby, I.C., Brent, L.J.N., Wroblewski, E.E., Rudicell, R.S., Hahn, B.H., Goodall, J. \& Pusey, A.E. (2013). Fitness benefits of coalitionary aggression in male chimpanzees. Behavioral Ecology and Sociobiology, 67, 373-381.

Harcourt, A.H. \& de Waal, F.B.M. (1992). Coalitions and Alliances in Humans and other Animals. Oxford University Press: Oxford.

Harcourt, A.H. (1992). Coalitions and alliances: are primates more complex than non-primates? In, Coalition and Alliances in Humans and other Animals (A.H. Harcourt \& F.B.M. de Wall eds), pp. 445-471. Oxford University Press: Oxford.

Higham, J.P. \& Maestripieri, D. (2010). Revolutionary coalitions in male rhesus macaques. Behaviour, $147,1889-1908$.

Hogg, J.T. \& Forbes, S.H (1997). Mating in bighorn sheep: frequent male reproduction via a high-risk "unconventional" tactic. Behavioral Ecology and Sociobiology, 41, 33-48.

Hsu, Y. \& Wolf, L.L. (2001). The winner and loser effect: what fighting behaviours are influenced? Animal Behaviour, 61, 777-786.

Jennings, D.J., Boys, R.J. \& Gammell, M.P. (2017). Investigating variation in third-party intervention behaviour during a fallow deer (Dama dama) rut. Behavioral Ecology, 28, 288-293. Jennings, D.J., Carlin, C.M. \& Gammell, M.P. (2009). A winner effect supports third-party intervention behaviour during fallow deer, Dama dama, fights. Animal Behaviour, 77, 343-348. 
Suffering intervention and mating success in fallow deer

490

491

492

493

494

495

496

497

498

499

500

501

502

503

504

505

506

507

508

509

510

511

512

513

Jennings, D.J., Carlin, C.M., Hayden, T.J. \& Gammell, M.P. (2011). Third-party intervention behaviour during fallow deer fights: the role of dominance, age, fighting and body size. Animal Behaviour, 81, 1217-1222.

Jennings, D.J., Gammell, M.P., Carlin, C.M. \& Hayden, T.J. (2004). Effects of body weight, antler length, resource value and experience on fight duration and intensity in fallow deer. Animal Behaviour, 68, 213-221.

Jennings, D.J., Gammell, M.P., Carlin, C.M. \& Hayden, T.J. (2006). Is difference in body weight, antler length, age or dominance rank related to the number of fights between fallow deer (Dama dama). Ethology, 112, 258-269.

Kruschke, J.K. (2015). Doing Bayesian Data Analysis. Academic Press: Amsterdam.

McDonald, A.L., Heimstra, N.W. \& Damkot, D.K. (1968). Social modification of agonistic behaviour in fish. Animal Behaviour, 16, 437-441.

Moore, N.P., Kelly, P.F., Cahill, J.P. \& Hayden, T.J. (1995). Mating strategies and mating success of fallow (Dama dama) bucks in a non-lekking population. Behavioral Ecology and Sociobiology, 36, 91-100.

Noë, R. (1992). Alliance formation among male baboons: shopping for profitable partners. In, Coalitions and Alliances (A.H. Harcourt, \& F.B.M. de Waal eds), pp. 233-257. Oxford University Press: Oxford.

Pallante, V., Stanyon, R. \& Palagi, E. (2016). Agonistic support towards victims buffers aggression in geladas (Theropithecus gelada). Behaviour, 153, 1217-1243.

Parker, G.A. (1974). Assessment strategy and evolution of fighting behaviour. Journal of Theoretical Biology, 47, 223-243.

Payne, R.J.H. (1998). Gradually escalating fights and displays: the cumulative assessment model. Animal Behaviour, 56, 651-662. 
Suffering intervention and mating success in fallow deer

514

515

516

517

518

519

520

521

522

523

524

525

526

527

528

529

530

531

532

533

534

535

536

Plummer, M. (2003). JAGS: a program for analysis of Bayesian graphical models using Gibbs sampling. In: Proceedings of the $3^{\text {rd }}$ International Workshop on Distributed Statistical Computing (DSC 2003). March, pp. 20-22.

Schilder, M.B.H. (1990). Interventions in a herd of semi-captive plains zebras. Behaviour, 112, 53-83.

Schuett, G.W. (1997). Body size and agonistic experience affect dominance and mating success in male copperheads. Animal Behaviour, 54, 213-224.

Silk, J.B. (1993). Does participation in coalitions influence dominance relationships among male bonnet macaques? Behaviour, 126, 171-189.

Silk, J.B., Alberts, S.C. \& Altmann, J. (2004). Patterns of coalition formation by adult female baboons in Amboseli, Kenya. Animal Behaviour, 67, 573-582.

Smith, J.E., van Horn, R.C., Powning, K.S., Cole, A.R., Graham, K.E., Meminis, S.K. \& Holekamp, K.E. (2010). Evolutionary forces favoring intragroup coalitions among spotted hyaenas and other animals. Behavioral Ecology, 21, 248-303.

Taylor, P.W. \& Elwood, R.W. (2003). The mismeasure of animal contests. Animal Behaviour, 65, 1195-1202.

van Schaik, C.P., Pandit, S.A. \& Vogel, E.R. (2006). Toward a general model for male-male coalitions in primate groups. In, Cooperation in Primates and Humans (P. Kappeler \& C.P. van Schaik (eds), pp. 151-171. Springer: Heidelberg.

Widdig, A., Streich, W.J., Nürnberg, P., Croucher, P.J.P., Bercovitch, F.R. \& Krawczak, M. (2006). Paternal kin bias in the agonistic interventions of adult female rhesus macaques (Macaca mulatta). Behavioral Ecology and Sociobiology, 61, 205-214.

Wolf, J.O. (1998). Breeding strategies, mate choice, and reproductive success in American bison. Oikos, 83, 529-544. 
Suffering intervention and mating success in fallow deer

538

539

540

541

542

543

544

545

546

547

548

549

550

551

552

553

554

555

556

557

558

559

560

561

562

List of Figures

Figure 1. The Elo-ratings achieved for each male on each day of the rut in both years of the study (panel A shows data from 1996 and panel B shows date from 1997). Each line represents the rating for one male.

Figure 2. The mean $(95 \% \mathrm{Cl})$ for the number of interventions suffered by individual males between the $14^{\text {th }}-31^{\text {st }}$ October in each year of the study (panel A shows data from 1996 and panel B shows date from 1997). Each bar represents one male.

Figure 3. The mean (and $95 \% \mathrm{Cl}$ ) for the number of interventions suffered between October $14^{\text {th }}-$ $31^{\text {st }}$ for each year of the study (panel A shows data from 1996 and panel B shows date from 1997). Figure 4. Summary of the parameter posterior distributions showing the dependence between the daily variation in mating success for individual males $(0=$ no mating, $1=$ mating $)$, and three regressors (including two interaction terms) for the logistic model. The three models showing the mean and $95 \%$ credible intervals for the proximate model $(\square)$, the delayed model $(\bullet)$, the cumulative model $(\boldsymbol{\Delta})$ are included. For each parameter the mean is denoted by the black shape and the $95 \%$ credible intervals by the thin line.

Figure 5. The proportion of matings achieved in relation to the number of fights engaged in, and the number of interventions suffered. Bars represent the $95 \%$ confidence intervals. Because the numbers of interventions suffered and fights engaged in per day decrease substantially at high values, we grouped the number of fights and number of interventions suffered in order to reduce the effect of outliers.

Figure 6. Summary of the parameter posterior distributions showing the dependence between the daily variation in mating success for individual males and three regressors (including two interaction terms) for the Poisson model. The three models showing the mean and $95 \%$ credible intervals for the proximate model $(\boldsymbol{\square})$, the delayed model $(\bullet)$, the cumulative model $(\boldsymbol{\Delta})$ are included. For each parameter the mean is denoted by the black shape and the $95 \%$ credible intervals by the thin line. 